\title{
PESQUISA COLABORATIVA: \\ CONTRIBUTO A PARTIR DE UM TRABALHO \\ COM IMIGRANTES NA CIDADE DE COIMBRA
}

\section{Elsa Lechner*}

\begin{abstract}
RESUMO
O texto discorre sobre a pesquisa colaborativa revisitando a genealogia dos trabalhos que nas ciências sociais e humanidades contribuíram para a sua definição. São analisados, em particular, os contributos dos autores de referência no desenvolvimento das formas de investigação participadas e de colaboração. No final é brevemente apresentado um projeto desenvolvido com imigrantes no Centro de Estudos Sociais da Universidade de Coimbra, baseado na realização de oficinas biográficas/rodas de histórias com participantes de dez nacionalidades diferentes, vários níveis de formação escolar, diversas religiões, homens e mulheres de diversas gerações.
\end{abstract}

Palavras-chave: Pesquisa colaborativa. Participação. Imigração. Portugal.

\section{ABSTRACT \\ COLLABORATIVE RESEARCH: CONTRIBUTIONS FROM A STUDY WITH IMMIGRANTS IN THE CITY OF COIMBRA}

This article discusses collaborative research, revisiting the genealogy of studies carried out in the social sciences and humanities that contributed to the definition of this concept. In particular, it analyzes the contributions of authors who played key roles in the development of participatory and collaborative forms of inquiry. Before concluding, the article takes a look at a project undertaken with immigrants at the Center of Social Studies at the University of Coimbra, which centered around biographical workshops/ circles of voices involving male and female participants of ten different nationalities, representing diverse generations, religions, and educational backgrounds.

Key words: Collaborative research. Participation. Immigration. Portugal.

\section{RESUMEN}

\section{INVESTIGACIÓN COLABORATIVA: CONTRIBUCIÓN A PARTIR DE UM TRABAJO COM INMIGRANTES EN LA CIUDAD DE COIMBRA}

El texto presenta la investigación colaborativa revisitando la genealogía de los trabajos que en las Ciencias Sociales y Humanas contribuyeron para su definición, Son analizados, en particular, las contribuciónes de autores de referencia en el desarrollo de las formas de investigación participativa y colaborativa. Al final es brevemnte

\footnotetext{
* Doutora em Antropologia Social pela École des Hautes Études en Sciences Sociales. Investigadora Principal no Centro de Estudos Sociais da Universidade de Coimbra. E-mail: elsalechner@ces.uc.pt
} 
presentado un proyecto desarrollado con inmigrantes en el Centro de Estúdios Sociales de la Universidad de Coimbra, fundamentado en la realización de talleres biográficos, grupos de conversación con participantes de diez nacionalidades diferentes, vários niveles de formación escolar, diversas religiones, hombres y mujeres de diversas generaciones.

Palabras Claves: Investigación colaborativa. Participación. Inmigación. Portugal.

\section{Introdução}

O presente texto ${ }^{1}$ visa definir a noção de pesquisa colaborativa numa leitura ancorada, simultaneamente, na genealogia teórica da literatura científica da especialidade e na prática concreta de uma pesquisa em colaboração no contexto português. ${ }^{2}$ Para tal, revisitamos os autores de referência, forjadores do termo, e seus seguidores herdeiros da investigação-ação, identificando uma perfeita atualidade dos seus pressupostos e objetivos comuns de trabalho no presente.

Segue-se uma apresentação de uma pesquisa desenvolvida no Centro de Estudos Sociais da Universidade de Coimbra, onde a nossa equipe pluridisciplinar de investigação coloca em prática oficinas de trabalho biográfico com imigrantes num formato colaborativo. ${ }^{3}$

Mostramos como a pesquisa colaborativa permanece um desafio tanto teórico, como prático e cívico. Entretanto constatamos também como a ousadia da experiência colaborativa num mundo desigual constrói bases de bem-estar comum útil a todas as partes envolvidas: academia, investigação científica, imigrantes, instituições públicas, senso comum (representações, comunicação, interconhecimento).

\section{Conceitos e aplicações: a colaboração como participação ativa na transformação social}

O termo "pesquisa colaborativa" designa,

1 Este texto foi inspirado na comunicação apresentada no X Seminário Internacional Imagens da cultura, cultura das imagens, realizado na ECA/USP, entre 28 e 30 de agosto de 2013.

2 Projeto de investigação Pesquisa das Migrações e Abordagem Biográfica: um Trabalho em Colaboração no Contexto Português, coordenado pela autora no Centro de Estudos Sociais da Universidade de Coimbra. Ref.: PTDC/CS-ANT/111721/2009 - FCOMP01-0124-FEDER-014442.

3 As oficinas biográficas foram objeto de um artigo por nós publicado na revista brasileira Educação e Realidade, em abril de 2012 (LECHNER, 2012). de forma abrangente, processos de investigação que recorrem a metodologias de investigação comprometidas ativamente com comunidades e/ ou fazedores de políticas públicas. Uma pesquisa colaborativa, segundo o University of California Center for Collaborative Research, implica três elementos centrais, sem os quais não pode existir: 1) orientada para a equidade; 2) realizada em formatos colaborativos; 3) trabalhando com comunidades.

Essa definição levanta várias questões que requerem precisão, desde logo no que se entende por "colaboração" e "comunidade" num contexto de investigação acadêmica e/ou científica. Mas antes de avançar para esse desenvolvimento conceitual, urge apresentar a genealogia teórica e prática deste tipo de investigação que se cruza e combina com a investigação-ação e pesquisa partilhada.

A investigação-ação (I-A) serve para resolver problemas imediatos ou levar a cabo um processo reflexivo sobre uma resolução progressiva de um problema social. É conduzida por equipes pluridisciplinares unidas sob o lema de uma "comunidade de práticas" com o objetivo de melhorar a compreensão e resolução de questões concretas afetando a vida de pessoas e instituições. É pragmática e autorreflexiva.

Kurt Lewin, psicólogo social especialista em relações de grupo nos EUA, foi quem concebeu esse termo nos anos 1940, no seguimento do pensamento de John Dewey (1938) sobre a educação pela experiência. Num texto seminal de 1946 intitulado Action Research and Minority Problems, Lewin (1946) descreveu a I-A como uma investigação conduzindo à ação transformadora em fases ou etapas em espiral. Cada etapa é composta por um ciclo sucessivo de planeamento, ação, e descoberta de fatos sobre o resultado dessa ação. O objetivo é transformar uma situação ou problema concreto.

A I-A não foi bem aceita nas Ciências Sociais durante muito tempo, por ir em contra-ciclo à 
preocupação de cientificidade e legitimação das mesmas em plena época de expansão do neoliberalismo econômico, sinônimo de contabilidade científica. Só mais recentemente a necessidade de combinar a investigação com a resolução prática de problemas sociais em áreas como a habitação, a saúde e o trabalho levou - com muita ênfase nos países nórdicos - ao reconhecimento e expansão da I-A. Hoje, tal como afirma Wilfred Carr (2013), a I-A é a própria elaboração da forma democrática de vida que ela visa criar e de que faz parte integrante aplicada à atividade de investigação.

No Brasil, os colegas Sergio Bairon e Caio Lazaneo utilizam o termo pesquisa partilhada no âmbito dos seus trabalhos em antropologia visual (BAIRON; LAZANEO, 2012). A pesquisa partilhada é herdeira direta da Educação Popular de Paulo Freire (1987) e irmã da pesquisa participativa comummente utilizada no mundo anglo-saxónico (CHEVALIER; BUCKLES, 2013). Os praticantes da pesquisa partilhada fazem um esforço concertado de integração de três aspectos básicos no seu trabalho: 1) a participação de todos os envolvidos na pesquisa, na sociedade e na democracia; 2) a ação (engajada com a experiência e a história); 3) a pesquisa para o avanço do pensamento e do conhecimento. O princípio que guia esta pesquisa é o do diálogo e pesquisa coletiva como fatores de desenvolvimento local e global. O que está em jogo é a prática do diálogo e a participação democrática na esfera do conhecimento e a sua aplicação a todos os níveis do nosso mundo "global", desde a vida numa comunidade de índios da Amazónia, até o funcionamento de organizações regionais, nacionais e internacionais (CHEVALIER; BUCKLES, 2013).

Para Chevalier e Buckles (2013), as questões sociais devem ser abordadas socialmente em conjunto pelas várias partes interessadas e não por interesses privados ou especialistas apenas. E as aprendizagens daí resultantes devem ser inteiramente integradas em processos de produção de conhecimento, planificação e decisão partilhados. Está aqui em causa um conhecimento vivo, com capacidade para fomentar o bem comum em nível mundial, com a participação dos atores sociais nas sofisticadas análises das suas próprias situações de vida. Os autores propõem, assim, uma noção ampla de "comunidade", que abarca o bem comum por todos a construir e partilhar.

Essa noção mais ampla de comunidade, na verdade, já se encontra no referido texto inaugural de Kurt Lewin (1946), no momento em que o psicólogo social refere que o problema das minorias é também um problema das maiorias: "O problema dos negros é o problema dos brancos, assim como o problema dos judeus é o problema dos não-judeus" (LEWIN, 1946, p. 44). E é na mesma lógica integrativa que a ideia de colaboração também é lançada por esse autor, através da sua sugestão de pensar a investigação e seus problemas em termos não generalistas mas existenciais, a partir da experiência concreta dos participantes na pesquisa. Cooperação é a palavra usada pelo autor, no horizonte de uma "gestão social com objetivos práticos” (LEWIN, 1946, p. 36). Quando, onde e por quem deve ser feita a investigação, são as perguntas a responder. O pressuposto é que se deve adotar "olhos e ouvidos sociais directamente nos corpos de ação" (LEWIN, 1946, p. 37).

Essa precisão genealógica dos conceitos de comunidade e colaboração é importante não apenas para fazer justiça a Lewin na sua antevisão, mas também porque na sua concepção mais ampla e integrativa da pesquisa colaborativa, a investigação, a ação e a formação configuram um triângulo dinâmico a manter intacto para o bem de cada uma das três dimensões do trabalho e para o bem comum.

O trabalho coletivo (como metodologia) e as relações intergrupais (como tema de estudo) constituíam para esse Professor do Massachussets Institute of Technology um dos aspectos mais cruciais das "cenas nacionais e internacionais". Podemos encontrar nestas cenas ou panoramas referidos pelo autor uma dimensão política da sua leitura e proposta. E a pertinência do trabalho com grupos para grupos parece manter-se na atualidade como no período pós-Segunda Guerra mundial. É quase assustador verificar que Lewin escreve em 1946 algo que podemos replicar nos nossos dias: "Sabemos hoje melhor do que nunca que elas [as relações intergrupais] são dinamite em potencial. A estratégia da investigação social deve tomar em consideração os perigos aí envolvidos" (LEWIN, 1946, p. 44). Sessenta e sete anos depois da sua afirmação, a mesma conflituosidade entre grupos 
sociais e países existe, como se a História não tivesse entretanto fornecido exemplos bastantes e gritantes das consequências nefastas desses mesmos conflitos. Sendo o preconceito e a luta pelo poder numa visão desintegrada do todo social e "comunitário" os principais ingredientes da discórdia, parece que a lição ainda está por aprender. Ou seja, a leitura e proposta desse autor dos anos 1940 mantêm-se atual, na necessidade de compreender e fazer investigação social como um trabalho coletivo, dialogante, participativo, exercendo na prática, através dos seus meios, o seu fim de construção do bem comum.

As áreas sociais, educativas e da saúde são as que mais têm aplicado a investigação-ação e pesquisa colaborativa e partilhada. É também de ressaltar o papel das artes, nomeadamente do teatro, neste esforço de compreensão das realidades sociais através do trabalho de grupo, do jogo de papéis, e consequente ação de inovação ou transformação social. O teatro do oprimido é o principal exemplo (BOAL, 1975), mas muitos outros se seguiram. Os seus objetivos são a democratização dos meios de produção teatral, o acesso das camadas sociais menos favorecidas a esta forma de expressão e a transformação da realidade através do diálogo e expressão teatral. ${ }^{4} \mathrm{O}$ mesmo se aplica a alguns trabalhos de arquitetura (BOUMAN, 2007), no mesmíssimo sentido da produção de conhecimento relevante para as pessoas com as pessoas. ${ }^{5}$

Nas ciências sociais a investigação-ação e pesquisa colaborativa/participativa foi, durante muito tempo, o parente pobre da atividade e produção científicas, como afirma José Ferreira de Almeida (2001). O mesmo autor registra também uma mudança significativa nesta tendência a partir dos anos 1980/90, com o exercício das profissões

\footnotetext{
4 A declaração de princípios da Associação Internacional do Teatro do Oprimido (OITO) indica, no primeiro ponto do seu preâmbulo, o objectivo de "Humanizar a Humanidade".

5 No âmbito do nosso projeto de investigação colaborativa no CES, realizámos em 2014 um curso co-organizado com os colegas do Departamento de Arquitectura da Universidade de Coimbra, no qual fizemos um exercício contínuo de diálogo e partilha interdisciplinares em torno de um Centro Comercial de Coimbra. Agora desinvestido pelos Conimbricenses, este espaço foi várias vezes mencionado pelo (as) imigrantes voluntários do projeto como um local de referência urbana das suas vidas na cidade. Curso Espaços e Transições: Partilhando Biografias e Projectos na Reinvenção do Centro Comercial Avenida (LECHNER; PROVIDENCIA; ALLEGRETTI, 2014).
}

do (as) antropólogo (as) e sociólogo (as) em terrenos sociais, tais como a habitação, luta contra a pobreza, saúde e em instituições outras que não a universidade. Um outro aspecto referido por Ferreira de Almeida é o enquadramento institucional de desenvolvimento da própria investigação científica, progressivamente marcado pelos princípios e objetivos do "Desenvolvimento tecnológico e da inovação". A palavra inovação parece ser, neste contexto, a versão tecnocrática da ideia de transformação social. Inovar é trazer algo de novo, como transformar também o é. No entanto, a conotação política da palavra "inovação" é menos poética e utópica do que a ideia de transformação. Entre estilos e tendências diferentes podemos, mesmo assim, encontrar uma idêntica preocupação, que só se distinguirá se os agentes e atores de cada uma destas agendas - transformação e inovação - voluntariamente associarem as suas ações a ideologias e grupos de poder. O que não é improvável, é claro.

De fato, tanto na União Europeia, como nos EUA, ou na Austrália, as políticas científicas desenham horizontes pautados por esses grandes chavões. Neste sentido, aumentou o financiamento de projetos de investigação interessados em agir diretamente sobre as realidades sociais. A título de exemplo, refira-se a criação em 2009/10 do Collaborative Research Network da Austrália (CRN), que contou, só nos primeiros dois anos de existência, com a atribuição de 81 milhões de dólares para a implementação de 15 projetos (AUSTRÁLIA, 2009). A agenda de inovação para o Século XXI, na qual se insere o CRN, sublinha o papel que a colaboração joga na promoção da investigação de ponta na Austrália e no mundo inteiro. Parece que os governos começam, agora, a praticar o que já havia sido sugerido por Lewin nos anos 1940.

Contudo os desafios mantêm-se. A colaboração requer parcerias igualitárias em contextos sociais marcados pela assimetria. Requer a partilha de poder, de recursos, créditos, resultados, saberes, bem como um apreço recíproco do saber e especificidade de cada parceiro. Trata-se de um processo interativo, que incorpora pesquisa, reflexão e ação num ciclo sucessivo de progressos em espiral.

Em seguida apresentaremos os desafios concretos enfrentados até agora no nosso referido projeto de investigação. 


\section{Os desafios do contato, relação, comunicação, coautoria}

O projeto "Pesquisa das migrações e abordagem biográfica: construindo um trabalho em colaboração no contexto português", financiado pela Fundação para a Ciência e Tecnologia, apresenta-se como uma proposta de trabalho em colaboração entre investigadores das ciências sociais e imigrantes residentes em Portugal. Mais especificamente procuramos estudar e conhecer a experiência migratória de imigrantes com origens (dez países diferentes) e perfis (homens, mulheres, trabalhadores, estudantes, desempregados, jovens, menos jovens, letrados, iletrados) muito diversos que escolheram - de uma forma ou de outra - a cidade de Coimbra para viver.

Os objetivos de partida desse trabalho decorrem do nosso foco privilegiado nas experiências e relatos biográficos dos sujeitos nossos interlocutores: ${ }^{6}$ 1) qual a perspectiva dos migrantes sobre a sua experiência migratória?; 2) qual o impacto da pesquisa na vida dos migrantes e sociedade de imigração?; 3) como reconhecer os sujeitos interlocutores para além de um propósito meramente objetificante da pesquisa?

Para tal, lançamo-nos ao terreno na cidade de Coimbra, ao mesmo tempo que fizemos uma pesquisa e análise da legislação portuguesa sobre imigração, bem como dos discursos midiáticos sobre a matéria em Portugal. Este confronto entre o discurso normativo sobre a imigração e as experiências concretas de migrantes "em carne e osso" é um aspecto central do nosso trabalho analítico, da nossa proposta metodológica baseada em oficinas biográficas, e do nosso esforço de sensibilização ou publicitação através dos resultados audiovisuais produzidos pelo projeto, tal como o filme documentário e o DVD do projeto.

Nesse sentido, e apesar de termos encontrado muitos obstáculos na procura de voluntários durante o primeiro ano (o desafio da entrada em contato e afinidade de motivações para a colaboração), as atividades realizadas em 2011 plantaram a semente de um trabalho de epistemologia cívica (JASANOFF, 2004a, 2004b) e de teoria aplicada que tem

6 Usamos o masculino universal nele incluindo todas as mulheres nossas interlocutoras, voluntárias do projeto e amigas. trazido outros desafios extremamente enriquecedores à nossa investigação e reflexão sobre formatos colaborativos, sobre o estudo das migrações com os próprios migrantes. As atividades em curso no ano de 2012, em contrapartida, fizeram germinar essas tentativas, criando oportunidades de encontro com comunidades migrantes, instituições públicas e serviços do Estado que concretizaram uma implicação crescente entre a equipe de investigação, os voluntários e as instituições locais.

Nesse segundo ano do projeto, o trabalho de campo consistiu no contato com instituições e pessoas suscetíveis de nos facilitarem o acesso a potenciais voluntários para as oficinas biográficas. Também desenvolvemos encontros e entrevistas individuais aos participantes no terreno. Tivemos uma primeira reunião com a Rede Social da Câmara Municipal de Coimbra (CMC) em janeiro de 2012. Esta reunião permitiu dar a conhecer o projeto e receber o apoio formal na procura de voluntários. De fato, na sequência deste primeiro encontro, foram agendadas novas reuniões entre a equipe de investigação e os técnicos de ação social da CMC, que nos puseram em contato com migrantes residentes na cidade de Coimbra: Serviço de Habitação, Cartão Família, nomeadamente. Realizamos um encontro com o Serviço de Habitação da Câmara no Bairro do Ingote em 30 de janeiro de 2012, data em que recrutamos alguns dos voluntários para as oficinas. Outros já haviam sido recrutados no meio universitário, onde há uma grande percentagem de estudantes estrangeiros com o estatuto legal de imigrante em Portugal e que demonstraram muita abertura e interesse em participar. No total, contatamos cerca de 100 pessoas, tendo mantido o contato regular com vinte. As instituições e mediadores foram decisivos nesta etapa de construção do trabalho em colaboração.

Em junho de 2012, fizemos uma apresentação pública do projeto, por ocasião do seminário "Rumina $C$ ções urbanas:"7 conte a sua cidade numa roda de histórias", na Casa da Cultura. Esta contou com a participação de alguns dos imigrantes contatados previamente, bem como com o responsável camarário pelo Serviço de Educação e Cultura.

7 Este título joga com a palavra "ação", indicando uma dupla função dos relatos experienciais na roda: ruminar (falar, mastigar, tomar consciência) e agir sobre o tema ou área em discussão, neste caso, a cidade. 
Só após estes contatos pudemos organizar duas oficinas biográficas (julho e outubro de 2012). Na primeira participaram apenas estudantes (oriundos de cinco países: Argentina, Brasil, Cabo Verde, China e Ucrânia); na segunda contamos com a presença de um grupo misto, bastante heterogêneo (estudantes, não estudantes, um imigrante iletrado) de sete países diferentes: Angola, Austrália, Brasil, Cabo-Verde, Costa do Marfim, São Tomé e Uzbequistão. Cada uma destas oficinas durou três dias e seguiu a mesma estrutura e protocolo de exercícios (escuta, partilha, ressonâncias) analisada no artigo já referido (LECHNER, 2012).

A realização dessas duas oficinas biográficas permitiu identificar grandes temas a aprofundar na análise do projeto. São eles a discriminação (dupla e tripla quando se trata de mulheres imigrantes negras e brasileiras solteiras ou divorciadas), o racismo - nomeadamente por parte dos serviços do Estado diretamente vocacionados para os imigrantes (como o Serviço de Estrageiros e Fronteiras nos seus atendimentos ao público) - e a importância das igrejas e religiões no acolhimento e redes de solidariedade dos imigrantes. Tanto a discriminação, como o racismo e as religiões, parecem envoltos num manto de inconsciência por parte de quem os pratica, contra a qual as oficinas biográficas muito contribuem graças ao formato circular e horizontal dos diálogos e aos seus efeitos formadores e transformadores. Realizamos uma oficina só sobre religiões em junho deste ano, com a participação de seis religiões diferentes (Batista, Católica, Espírita, Candomblé, Messiânica, Mórmons, Muçulmana), na qual os vários participantes referiram o seu espanto em ver e sentir tanto respeito entre pessoas de credos diferentes.

Sem dúvida que o trabalho de contato com os voluntários do projeto e das oficinas biográficas pôs a nu o desafio que é tentar fazer colaboração em contextos sociais de assimetria. E precisamente porque se tornou tangível na nossa experiência de investigação esta diferença estrutural entre os mundos da universidade e o mundo "lá fora" da imigração (menos evidente na primeira oficina com estudantes), organizamos a terceira e quarta oficinas diretamente focadas na questão das mulheres $^{8}$ (março de 2013) e das religiões (junho de

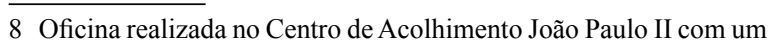

2013), onde pudemos conhecer experiências outras que trouxeram um nível maior de alteridade para o nosso trabalho colaborativo. Neste confronto de realidades ficamos, por exemplo, sabendo da existência de uma Mesquita na cidade de Coimbra, desconhecida inclusive da Rede Social da Câmara Municipal. Foi, aliás, através do nosso projeto que os técnicos daquele serviço da CMC tomaram conhecimento da existência da Mesquita.

Assim, percebemos como a colaboração em contextos de assimetria social ou estatutária (entre nacional/estrangeiro; universitário/iletrado, etc.) leva a reciprocidades assimétricas (TEMPLE, 2003) que trazem para o coração do processo de trabalho colaborativo com imigrantes uma alteridade potenciadora de mútua aprendizagem e diálogo transformador. Tanto esta aprendizagem recíproca, como o diálogo transformador, por sua vez, podem ser conducentes a uma ação inovadora na esfera coletiva. Para que isso aconteça, é preciso que ambas as partes queiram agir nesse sentido construtivo aquém e além dos estatutos sociais de partida. $\mathrm{Ou}$ seja, como diria Temple (2003), é preciso que o valor material da troca não se sobreponha ao valor simbólico do que é partilhado. Ou ainda, é preciso que os valores simbólicos associados aos diferentes estatutos sociais de partida não bloqueiem a possibilidade de transformação do peso dos mesmos na produção compartilhada do valor da responsabilidade e autoria comuns. E aqui mesmo encontramos novos desafios, nomeadamente o da relação e da comunicação entre pessoas com culturas, línguas e linguagens diferentes.

Ora, uma das ferramentas mais úteis para trabalhar "por dentro" estes desafios teóricos, metodológicos e cívicos da colaboração é o registro e análise das imagens do próprio processo de trabalho. Assim, temos a totalidade das horas em oficina biográfica (60 horas) filmada e gravada com autorização de todos os participantes. Houve apenas um participante que, no início, não quis ser filmado. Mas justamente após prestar o seu testemunho (um dos primeiros) sobre a discriminação e racismo que sentiu no balcão de atendimento do SEF (Loja do Cidadão), o próprio reconheceu a importância dessa experiência tornar-se conhecida

grupo de mulheres do Brasil, Guiné Bissau, Moçambique e Ucrânia, beneficiárias das ajudas sociais do Centro. 
por um público maior e anônimo. Desta forma, temos um corpus audiovisual riquíssimo que está sendo objeto de análises direcionadas por temas, e que fará parte do DVD sobre o projeto, bem como do filme documentário que iremos realizar com os voluntários sobre o tema da imigração.

\section{A construção colaborativa do Centro Comercial Avenida como tema (involuntário) do projeto}

$\mathrm{Na}$ segunda oficina biográfica do projeto, realizada com um grupo misto em outubro de 2012 , surgiu de imprevisto e tema do Centro Comercial Avenida (CCA), um shopping construindo nos anos 1980 numa avenida central da cidade (Av. Sá da Bandeira), após demolição de um teatro do século XIX, único onde se cantava Ópera em Coimbra. Envolto em polêmica, o CCA foi erguido antes dos grandes centros comerciais Forum e Dolce Vita, que vieram, no final dos anos 1990, decretar o declínio comercial do CCA. Assim, hoje, este centro comercial mais antigo encontra-se desinvestido pelos comerciantes e consumidores, oferecendo valores baixos de aluguel que atraem pequenos empresários menos capitalizados.

O CCA aparece no nosso projeto pela primeira vez pela voz de uma participante australiana, missionária de uma Igreja Batista com sede no $4^{\circ}$ piso desse centro comercial. Passamos a apresentar o sumário dos trechos minutados.

\section{Dia 25 de Outubro}

Câmera 2, clip 140, minuto 27, aproximadamente. Louise $^{9}$ (missionária australiana de uma Igreja Baptista) fala da festa anual dos hindus no Avenida, onde ela tem a Igreja. O tema surge na sequência da fala de Abdurafik, acerca da festa dos muçulmanos na mesma data. $\mathrm{O}$ excerto da sua intervenção informa sobre o início do ano hindu naquele dia, a comida, as danças, o número de participantes hindus ('uns trinta') nas festas. É mesmo à frente da sua Igreja que este grupo se reúne, no $4^{\circ}$ piso, numa loja indiana de incensos e roupas, ao lado de um 'café dos Bangladeshis onde se come momos (raviólis nepaleses)'. Ela termina com a avaliação da diversidade.

9 Todos os participantes no projeto autorizaram a citação dos nomes. São colaboradores e não cobaias.

\section{Dia 26 de Outubro}

Câmera 2, clip 087, minuto 18 aproximadamente, Louise, durante um balanço do dia anterior, fala que jantou comida indiana, momos a 2 euros no Avenida. Abdurafik diz que conhece o sítio, Sr. Arsénio pergunta onde é, e lembra que foi lá que comprou o telemóvel. Louise insiste na 'propaganda' do momo a 2 euros.

Câmera 1 , clip 85, minuto 5 aproximadamente, Lucy está a contar a sua história, conta que teve muita dificuldade em trabalhar como cabeleireira e que depois de ter feito um curso de estética abriu um salão de cabeleireira no Avenida. Clara e Elsa reforçam o Avenida, Louise pergunta em que andar, Clara pergunta se ela e Louise se conheciam, e Alda olha para Lucy, quando ela fala do Avenida. Momento crucial.

\section{Dia 27 de Outubro}

Câmera 2, clip 90, minuto 23 aproximadamente, Alda, falando da sua situação financeira é convidada por Elsa a falar da condição do seu marido. Diz que o marido sai de casa todos os dias, dando a entender que não sabe bem o que ele faz, e diz que ele tem um escritório no Avenida. Louise insiste em perguntar o andar, Elsa diz a Clara que o Avenida tem que entrar no filme.

Câmera 1, clip 99, minuto 13 aproximadamente, Maria da Penha, contando a sua história diz que o mais difícil de ficar em Portugal foi o cabelo, porque não tinha um salão onde soubessem tratar dele. Conta então que foi ao Avenida, à procura de um cabeleireiro Afro que lhe tinha sido indicado, e relata o momento de encontro com Lucy, no quarto piso do Avenida. Lucy complementa a história. São duas narrativas de um mesmo acontecimento.

\section{Dia 23 de Março}

Câmera 1, clip 09, minuto 30 aproximadamente, Socorro fala que há um lugar que tem advogados para imigrantes na sequência da fala da Flávia, acerca do desconhecimento da lei da imigração. Socorro diz que viu na Junta de Freguesia dos Olivais que, no shopping Avenida, tem um escritório de advogados para imigrantes. Elsa pergunta onde (querendo saber qual o piso) e Socorro fala na Avenida Sá da Bandeira, mas não sabe o piso.

Cada um desses excertos constitui um momento de construção involuntária do CCA como tema relevante do projeto. O CCA é um lugar de referência 
para essas pessoas, traduzindo uma pertinência que ultrapassa a experiência singular de cada um. Uma análise mais detalhada dos relatos acima resumidos revela ainda mais elementos significativos deste momento de co-construção (análise linguística, interacionista).

A partir dessa evidência, digamos assim, o CCA tornou-se tema de diálogo interdisciplinar com os nossos colegas arquitetos do CES. Sendo eles docentes do curso de pós-graduação em arquitetura, interessaram-se pela participação da equipe e voluntários do projeto numa ação conjunta junto dos estudantes. Nasceu assim a ideia de organizarmos um curso de verão sobre o CCA, numa tentativa de diálogo e investigação interdisciplinares entre todos os interessados.

Antes disso, o CCA se havia tornado um catalisador temático para o filme documentário que planejamos realizar em colaboração com os participantes das oficinas.

Assim, fomos com a equipe técnica do Canal televisivo da Universidade de Coimbra ao CCA fazer filmagens, tendo como guias os participantes que trouxeram este espaço arquitetônico e urbanístico para o projeto. A ideia foi seguir os mapas mentais e experienciais destes participantes no que diz respeito àquele lugar, sobrepondo-os num jogo de diálogo que vai acrescentando vida ao espaço: os momos nepaleses (comida, cheiros, cultura), o cabeleireiro afro (corpo, texturas, segregação racial), os telemóveis (comunicação), o escritório do marido (trabalho), o café dos bangladeshis (comunidade de pertença, identidade étnica e nacional), a igreja Batista (religião), os advogados dos imigrantes (lei). O guião foi elaborado em conjunto depois de reunir todos os participantes numa roda, após o trabalho fotográfico e as filmagens no Centro Comercial Avenida. Sugerimos que cada participante pensasse "no seu filme" e que trouxessem também registros fílmicos autobiográficos para o projeto. Este desafio foi lançado desde o início dos contatos entre a equipe de investigação de partida e os voluntários aderentes à proposta. Em abril de 2013 reunimos os três grupos das primeiras oficinas numa roda maior para falar do filme. Percebemos o entusiasmo de todos mas também uma certa passividade ou inação, tendo em conta os poucos registros trazidos até agora. Esta é uma colaboração que partiu da nossa iniciativa e não de qualquer instituição ou comunidade. Por essa razão, não temos ilusões quanto ao peso decisivo da nossa intenção na experiência colaborativa. Em contrapartida, também somos bem realistas quanto ao valor decisivo da participação dos voluntários na produção de um conhecimento equitativo, coerente com a proposta de agir conhecendo com os sujeitos no terreno. Sem eles e elas este trabalho não poderia existir.

Solicitamos a todos os participantes um balanço da experiência nas oficinas biográficas e uma avaliação do trabalho. Todos referem a importância do formato, do diálogo, da escuta e de tornar conhecidas as experiências concretas de quem vive a imigração. Mais do que dar voz aos imigrantes, neste sentido, o projeto de construir um trabalho em colaboração com Abdurafik, Alda, Arsénio, Bernardino, Cristina, Dália, Elisabete, Flávia, Kouassi, Lluba, Lucy, Maria da Penha, Reginaldo, Rosana, Rosantina, Shaknoza, Socorro, Viktoria e Virgílio, traduz uma vontade de contribuir para o conhecimento da imigração e seus problemas e potencialidades numa ação conjunta de interconhecimento e aprendizagem. Para tal, é decisivo o trabalho das oficinas biográficas, bem como os suportes audiovisuais usados em produtos hipermídia e no filme documentário.

\section{Uma nota conclusiva: para tudo o que falta dizer...}

Este texto inicia um enquadramento da experiência concreta de trabalho colaborativo que desenvolvemos no Centro de Estudos Sociais da Universidade de Coimbra com imigrantes. Trata-se de um primeiro momento de confronto entre o quadro teórico da investigação-ação e pesquisa partilhada, tal como as nossas referências as definem, e o nosso projeto. Para tal, revisitamos os fundadores desta literatura científica que, na nossa opinião, se caracteriza justamente por ser também uma literatura cívica e mesmo de uma economia humana ou moral social, centradas numa noção democrática de cidadania participativa.

Lançamos os primeiros tijolos informativos da descrição deste trabalho de uma forma sumária. Mui- 
to mais haveria a dizer sobre a entrada no terreno, a manutenção dos contatos ao longo do tempo, o estabelecer de relações, o trabalho nas oficinas, o trabalho de preparação do filme a realizar. São muitas horas de diálogo, de encontros formais, informais e não formais, entre todas as pessoas envolvidas. Não há espaço neste artigo para esse material e análise.

Preparamo-nos para fechar este contributo pontual com o sentimento e a consciência de que há muito mais para discorrer. Com tinta, imagens, fotografias, vídeos, desenhos, comidas e outras formas de expressão, e iniciativas conjuntas, seja com colegas portugueses ou outros. O nosso intuito e vontade é aprofundar o diálogo e o conhecimento teórico-prático sobre pesquisa colaborativa.

\section{REFERÊNCIAS}

AUSTRÁLIA. Australian Government. Department of Industry, Innovation and Science. Collaborative Research Network. 2009. Disponível em: <http://www.innovation.gov.au/CRN>. Acesso em: 10 ago. 2013.

BAIRON, S.; LAZANEO, C. Produção partilhada do conhecimento: do filme à hipermédia. CONGRESSO BRASILEIRO DE CIÊNCIAS DA COMUNICAÇÃO, 35., 2012, Fortaleza. Anais... Fortaleza, 2012.

BOAL, Augusto. Teatro do oprimido e outras poéticas políticas. Rio de Janeiro: Civilização Brasileira, 1975.

BOUMAN, Ole. Unsolicited, or: the new autonomy of architecture. Archis, n. 4, 2007.

CARR, Wilfred. Education, democracy and action research. Paper at the Collaborative Action Research Network (CARN) conference in Tromsø, North Norway, 7th - 9th November 2013.

CHEVALIER, J.; BUCKLES, Daniel J. Participatory action research, theory and methods for engaged inquiry. London, UK: Routledge, 2013.

DEWEY, John. Experience and education. Indiana, USA: Kappa Delta, 1938.

FERREIRA DE ALMEIDA, José. Em defesa da investigação-acção. Sociologia: Problemas e Práticas, n. 37, p. 175-176, 2001.

FREIRE, Paulo. Pedagogia do oprimido. 27. ed. Rio de Janeiro: Paz e Terra, 1987.

JASANOFF, Sheila. Science and citizenship. Science and Public Policy, n. 31, p. 90-94, 2004a.

States of knowledge: the co-production of science and social order. London, UK: Routledge, 2004b.

LECHNER, Elsa. Oficinas de trabalho biográfica: pesquisa, pedagogia e ecologia de saberes. Revista Educação e Realidade, Porto Alegre, v. 37, n. 1, p. 71-87, 2012.

LECHNER, Elsa.; PROVIDENCIA, Paulo; ALLEGRETTI, Giovanni. Apresentação e programa do Curso de Verão. Espaços e transições: partilhando biografias e projectos na reinvenção do Centro Comercial Avenida. Coimbra, PT: CES, 2014. Disponível em: <http://www.ces.uc.pt/eventos/index.php?id=8903\&id_lingua=1>. Acesso em: 27 jan. 2014.

LEWIN, Kurt. Action research and minority problems. Journal of Sociological Issues, v. 2, n. 4, p. 34-46, 1946. TEMPLE, Dominique. Teoría de la reciprocidad. La Paz: PADEP/ GTZ, 2003.

Recebido em: 19.08 .2015

Aprovado em: 17.10 .2015 